\title{
Chapter 11 \\ Seismic Performance of Historical Masonry Structures Through Pushover and Nonlinear Dynamic Analyses
}

\author{
Sergio Lagomarsino and Serena Cattari
}

\begin{abstract}
Earthquakes are the main cause of damage for ancient masonry buildings. In order to reduce their vulnerability with compatible and light interventions, it is necessary to have accurate models for the seismic analysis, able to simulate the nonlinear behaviour of masonry, and well defined Performance-Based Assessment (PBA) procedure, aimed to guarantee acceptable levels of risk for the use of the building, the safety of occupants and the conservation of the monument itself. Displacement-based approach is the more appropriate for this type of structures, which cracks even for low intensity earthquakes and can survive to severe ones only if they have a sufficient displacement capacity. Among the wide variety of historical masonry structures, buildings characterized by a box-type behavior are here considered, which can be modeled through the equivalent frame model, considering the assembling of nonlinear piers and spandrels. Thus, the main object of the paper is to establish a strict equivalence between the use of static pushover and incremental dynamic analyses for the PBA. Pros and cons of the two methods are discussed, as well as some critical issues related to their application. A multiscale approach is proposed for the definition of the performance levels, which considers the seismic response at different scales: local damage in single elements, performance of single walls and horizontal diaphragms and global behavior. An original contribution is the use of Proper Orthogonal Decomposition (POD) technique for the correct interpretation of numerical and experimental dynamic results.
\end{abstract}

\footnotetext{
S. Lagomarsino $(\bowtie) \cdot S$. Cattari

Department of Civil, Chemical and Environmental Engineering, University of Genoa, Via

Montallegro 1, Genoa 16145, Italy

e-mail: sergio.lagomarsino@unige.it; serena.cattari@unige.it
}

A. Ansal (ed.), Perspectives on European Earthquake Engineering and Seismology, Geotechnical, Geological and Earthquake Engineering 39,

DOI 10.1007/978-3-319-16964-4_11 


\subsection{Introduction}

Seismic safety evaluations of existing masonry buildings aim to assess whether retrofitting interventions are needed. In the case of historical buildings, conservation principles require that interventions are minimized to protect as much as possible heritage values (beside the ensuring of people safety and durability of original materials). In order to demonstrate that a structural intervention is necessary (in the sense that the building is not safe enough) and effective (in the sense that the intervention is able to achieve a satisfactory safety level), the structural engineer should be able to: (i) minimize the modelling uncertainties of the current structural behaviour and after structural modifications; (ii) adopt accurate and reliable models to predict the seismic response; (iii) adopt reliable criteria for the safety assessment.

Therefore, quantitative and reliable procedures for the evaluation of the seismic safety index of the structure are required. In the last decade, an increasing number of codes for the assessment of existing buildings were published (e.g. EC8-Part 3 2005; ASCE 41-13 2014; CNR DT 212 2013; SIA 269/8 2013). In the case of historical buildings, due to their complex configuration, many recommendations (ICOMOS 2005; ISO 13822 2010; CIB 335 2010) stress the importance of the qualitative approach. However, while a qualitative assessment is usually sufficient for the diagnosis in many critical situations, such as material deterioration or soil settlements, the evaluation of seismic vulnerability without the support of calculations is overambitious; in this case, the qualitative approach and the historical analysis can only suggest which is the expected seismic behaviour, but they are not sufficient to prove the building safety. This is the reason why the Italian Guidelines for the seismic assessment of cultural heritage (P.C.M. 9/2/2011) clearly state that quantitative calculation of the structural safety are necessary and recent research trends (e.g. the PERPETUATE project - Lagomarsino and Cattari 2015; Lagomarsino et al. 2010) are focused on the proposal of proper quantitative procedures also in the case of monumental buildings.

Within this context, the Performance-Based Assessment (PBA) requires the use of nonlinear analyses for the verification through the Displacement-Based Approach (DBA). In fact, due to the high vulnerability of different types of historical structures, which was proved again by the recent earthquakes (Oliveira 2003; Lagomarsino 2012; Cattari et al. 2013; Sorrentino et al. 2013), nonlinear models turn out to be essential for an accurate and reliable assessment, due to the strongly nonlinearity of masonry, despite the complexity of these buildings, both from a geometric and structural point of view.

The mechanical models widely used at present for the analysis of ancient masonry structures consider a verification approach in terms of forces: the consequence is that in the past strengthening techniques were aimed at increasing stiffness and strength. However, earthquake induces deformations and dynamic amplification; therefore, it is better to keep the original flexibility of the structure 
and improve the displacement capacity, in terms of ductility or rocking, in order to survive even to rare destructive earthquakes.

This agrees also with the PBA concepts, which consider different Performance Levels (PLs) that must be fulfilled in the occurrence of corresponding earthquake hazard levels (defined by the return period). The need to check the achievement of PLs that are close to structural collapse strongly strengthens the use of static nonlinear models and displacement-based procedures for the assessment, as it is not possible to rely on linear analyses with the behavior factor approach, being existing buildings not capacity designed.

Nonlinear static (pushover) analysis is usually considered as the main tool for the application of the DBA; the vulnerability of the building is described by its capacity curve. Recently, nonlinear dynamic analysis is emerging as a proper alternative tool, which allows to evaluate the capacity, for example, through an Incremental Dynamic Analysis (IDA, Vamvatsikos and Cornell 2002); IDA curves are obtained through the application of a proper number of selected records, by scaling the Intensity Measure (IM) till to reaching the given performance. The two approaches have pros and cons, but an equivalence between them and a clear definition on how to use both in an integrated way is still missing.

The paper focuses on this problem, paying particular attention to the specific issues posed in the case of existing and historical masonry buildings characterized by a box behavior, for which a 3D equivalent frame model of the whole building is appropriate (e.g. Lagomarsino et al. 2013). This modeling approach considers the in-plane behavior of masonry walls, which are discretized by piers and spandrels, connected by rigid nodes, in order to create a plane frame. Piers are vertical panels and are the most important elements since they resist both gravity loads and seismic action; spandrels are the horizontal elements between two vertically-aligned openings and connect two piers, limiting their end rotations. Each element is described by nonlinear constitutive laws, in terms of generalized forces $(\mathrm{N}, \mathrm{V}, \mathrm{M})$ and displacements $(u, v, \varphi)$, defined by proper failure criteria (e.g. as illustrated in Calderini et al. 2009; Beyer and Mangalathu 2013, for piers and spandrels respectively) and drift limits (e.g. as recently discussed in Petry and Beyer 2014); in addition, in case of nonlinear dynamic analyses, the definition of an accurate cyclic hysteretic behavior is required. Moreover, the possibility of modeling flexible diaphragms (timber floors, masonry vaults), aimed to properly simulate the redistribution of seismic actions among walls, constitutes an essential requisite for a reliable assessment (Lagomarsino et al. 2013).

The equivalent frame modeling approach (explicitly suggested by some codes as the EC8-Part 3) allows the nonlinear analysis (static and dynamic) of complex models with a reasonable computational effort, and its use is widespread not only at research level but also in engineering practice.

However, in the case of complex masonry historical structures, many aspects need to be investigated in terms of equivalence and compatibility of static and dynamic approaches, such as how to consider the contribution of higher modes in static pushover analysis or to define Damage Levels (DL) and related PLs. As regard the first issue, pushover analysis investigates the behavior of the structure 
under a predefined mode, induced by a given load pattern, monotonically increased; thus the effects of higher modes, which induce a widespread diffusion of the damage (as it is observed from nonlinear dynamic analyses), are lost. As regard the second issue, the main problem is that the criteria currently adopted in codes, based on the attainment of drift thresholds in structural elements or directly related to the pushover curve through heuristic criteria, are not effective to detect the actual behavior of such complex buildings, irregular in plan and with flexible horizontal diaphragms.

In the following, all the aforementioned issues are deepened and some solutions are proposed. In particular, the use of the Proper Orthogonal Decomposition (POD) technique is suggested to process results of nonlinear dynamic analyses $(\S 11.4)$ and the multiscale approach is proposed to define the DLs $(\$ 11.5)$.

\subsection{Seismic Performance-Based Assessment Through Nonlinear Static and Dynamic Analyses}

Seismic PBA of an existing building checks if the construction is able to fulfill some selected Performance Levels (PLs) in case of occurrence of corresponding earthquake hazard levels, defined by the annual rate of exceedance $\lambda$ (or return period $\mathrm{T}_{\mathrm{R}} \approx 1 / \lambda$ ). Once a proper Intensity Measure (IM) has selected as the one better correlated with the building capacity, the maximum IM compatible with the fulfillment of each PL that has to be checked $\left(\mathrm{IM}_{\mathrm{PLk}}, \mathrm{k}=1, . .4\right.$ if four PLs are considered) is adopted as relevant outcome of the assessment. In the case of historical buildings, target PLs have to be defined by considering not only the use and safety of people (as usually proposed in codes in the case of new and existing ordinary buildings) but also the conservation of the valuable architectural and artistic assets of the monument: this issue has been recently faced in PERPETUATE project (Lagomarsino et al. 2010) by proposing specific PLs that include also requirements related to the Building Conservation and Artistic Asset Conservation (Lagomarsino and Cattari 2015). According to this proposal, for example in the case of Building Conservation, the preservation from building damage is not related, as for ordinary buildings, to the costs of repair or rebuilding but to the possibility of restoration or to the collapse prevention, in order to maintain, at least, the monument as a ruin.

Within this general framework, Fig. 11.1 summarizes the basic principles and steps of the PBA procedure, if nonlinear static or dynamic analyses are adopted.

The first step requires the definition of the seismic input. It is defined by the hazard curve, obtained through a Probabilistic Seismic Hazard Analysis (PSHA), which gives the selected IM as a function of the annual probability of occurrence (or the return period). Peak Ground Acceleration (PGA) is the most frequently adopted IM, due to the large amount of information (strong motion records) and models (Ground Motion Prediction Equations - GMPEs) that are available; it is 
a NonLinear Static Analysis (NLSA)

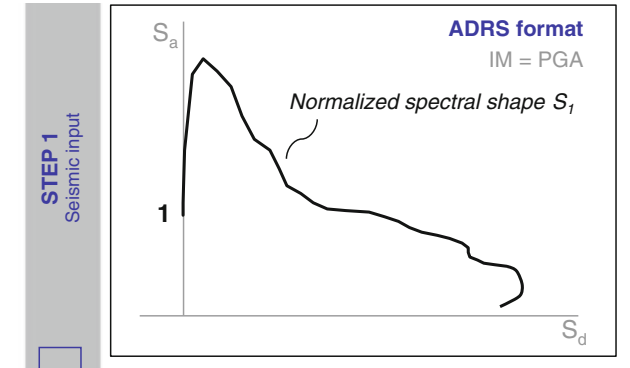

C Multiscale approach for PLs C

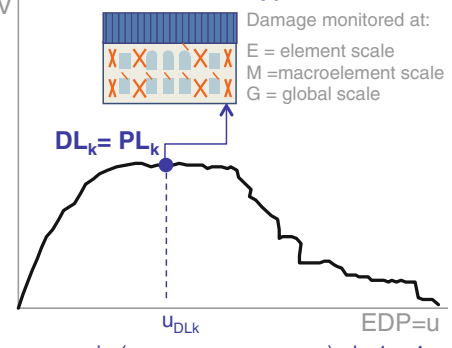

$\mathrm{u}_{\mathrm{DLk}}=\min \left(\mathrm{u}_{\mathrm{E}, \mathrm{DLk}} ; \mathrm{u}_{\mathrm{M}, \mathrm{DLk}} ; \mathrm{u}_{\mathrm{G}, \mathrm{DLk}}\right) \quad \mathrm{k}=1, \ldots, 4$

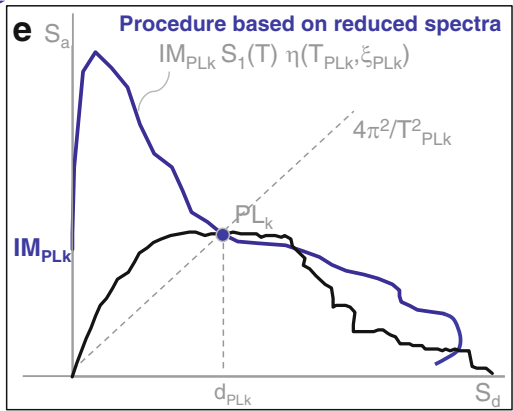

b NonLinear Dynamic Analysis (NLDA)
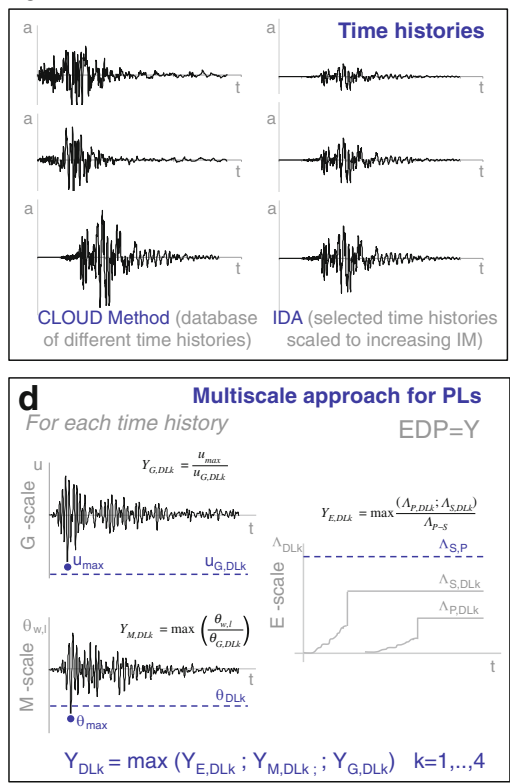

f Statistical evaluation of $\mathrm{IM}_{\mathrm{PLk}}$

Cloud Method $\rightarrow$ Multiple Stripe Analysis

$\mathrm{IDA} \rightarrow$ Probability density function of $\mathrm{Y}_{\mathrm{PLK}}=1$

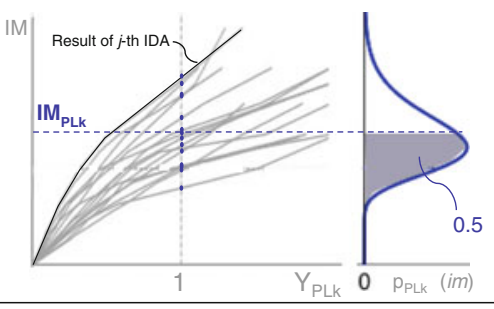

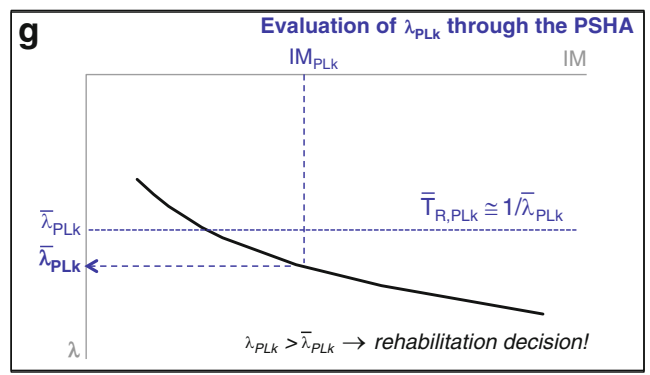

Fig. 11.1 Principles of PBA through nonlinear static and dynamic analyses

usually a good parameter in the case of masonry palaces characterized by a box behavior, due to their relatively short natural period, or of massive structures. Other possible IMs are the spectral acceleration for a significant period of vibration of the 
asset, the maximum spectral displacement, Arias intensity and Housner intensity (Douglas et al. 2015). Advices on the proper selection of IM as a function of various architectural assets (towers, obelisks, single or multi-drum columns, ..) are proposed in Lagomarsino and Cattari (2015).

In the case of NonLinear Static Analysis (NLSA), the seismic input (Fig. 11.1a) is described by an Acceleration-Displacement Response Spectrum (ADRS), which must be completely defined, for the specific site of the building under investigation, as a function of the assumed IM. On the contrary, in the case of NonLinear Dynamic Analysis (NLDA) it is represented by a proper set of time histories (Fig. 11.1b). The ADRS may be defined: (1) analytically, as in seismic codes; (2) through a piecewise linear function, by spectral acceleration values $S_{a}\left(T_{h}\right)$ for a given set of periods $T_{h}(h=1, \ldots, N)$, obtained from GMPEs that already includes the soil amplification effects; (3) as the mean of the time histories selected to be representative of the expected seismic events for the examined area. NLDA may be performed by using a large amount of records (cloud method) or a proper selection of time-histories, scaled in order to perform an IDA. These latter may be selected from real recorded accelerograms (in order to be equivalent, on average, to the target ADRS) or obtained through numerical modeling of the fault mechanism and the propagation towards the site.

Once defined the seismic input, the second step deals with the definition of proper thresholds for PLs correlated to the seismic response of the structure. To this end it is useful to make reference to the empirical definition, adopted in macroseismic post-earthquake assessment (Grunthal 1998), of observational Damage States (DS): (1) slight; (2) moderate; (3) heavy; (4) very heavy; (5) collapse. The behavior of the structure may be described by an Engineering Demand Parameter (EDP), such as the horizontal displacement at the top of the building, which can be evaluated by the static or dynamic nonlinear analyses and is useful, through properly defined thresholds, to identify Damage Levels (DL) on the pushover curve (in case of NLSA) or on the IDA curve (in case of NLDA); DLk $(\mathrm{k}=1, \ldots, 4)$ is the point after which the building experiences DSk. Then, DLs, which are directly related to the structural response, have to be correlated to PLs, which represent the behavior of the building in terms of functionality and consequences (like as the immediate occupancy or the life safety). A first approximation is to establish a direct correspondence between DLs and PLs. For example, Life Safety is usually associated with heavy damage threshold (DL3), because it is assumed there are very few casualties or injured people with this damage level. From a probabilistic point of view, the attainment of the threshold that corresponds to DLk means the probability of being in a DS greater of equal to DSk is $50 \%$. By using statistical correlations between DSs and losses (in terms of casualties and injured people, homeless, costs of repair), derived from post-earthquake assessment (Coburn and Spence 2002), a refinement of such acceptance criteria is possible (Lagomarsino and Cattari 2015).

As introduced in $\$ 11.1$, the definition of reliable criteria to correlate DLs with the structural response is a challenging task in the case of complex masonry assets. Herein a multiscale approach $(\$ 11.5)$ is proposed by considering the behavior of 
single elements (E), macroelement (M) and of the global building (G). For each scale, proper variables are introduced and their evolution in nonlinear phase is monitored: local damage in piers and spandrels (E); drift in masonry walls and horizontal diaphragms (M); normalized total base shear, from global pushover curve $(\mathrm{G})$. At the end, the EDP associated to the attainment of the given DLk is represented in the case of NLSA by the displacement plotted in the pushover curve $(\mathrm{u})$ : the corresponding threshold $\left(\mathrm{u}_{\mathrm{DLk}}=\mathrm{u}_{\mathrm{PLk}}\right)$ derives from the application of such multiscale approach as the minimum value (see Eq. 11.4 in §11.5) coming from the reaching of predefined limit conditions at the aforementioned scales (Fig. 11.1c). In case of NLDA, the results of each single analysis have to be properly processed. To this aim and coherently with the multiscale approach adopted in NLSA, a scalar variable $\mathrm{Y}_{\mathrm{DLk}}\left(=\mathrm{Y}_{\mathrm{PLk}}\right)$ is introduced as EDP (Fig. 11.1d): it derives from the maximum among proper ratios between the maximum value (see Eq. 11.9 in $\S 11.5)$ of the variables monitored at three different scales, reached through the application of the selected record, and the corresponding threshold. It is assumed that the attainment of $Y_{\mathrm{DLk}}=1$ indicates the reaching of the examined DL. A more thorough description of the multiscale approach is illustrated in §11.5.

Once introduced the EDP and criteria to define the PLs, it is possible to pass to the computation of $\operatorname{IM}_{\mathrm{PLk}}$ (third step). In the case of NLSA (Fig. 11.1e), IM $\mathrm{ILEk}_{\mathrm{PL}}$ is obtained by the evaluation of the IM for which the seismic demand, given by a properly reduced (overdamped or inelastic) ADRS, is equal to the displacement capacity, related to the previously defined threshold of the EDP for the specific PL. The capacity curve is obtained by converting the pushover curve (obtained from the MDOF model of the building) into the equivalent nonlinear SDOF system. Herein, the Capacity Spectrum Method (Freeman 1998) with overdamped spectra is adopted as reference with some modifications illustrated at $§ 11.6$. In the case of NLDA, numerical results may be represented by plotting the scalar variable $Y_{D L k}$ as function of IM (Fig. 11.1f). Then the procedure is based on a statistical evaluation of $\mathrm{IM}_{\mathrm{PL}}$ through the Multiple Stripe Analysis (MSA, as described for example in Jalayer e Cornell 2009), in the case of cloud method, or on the IDA curve in correspondence of the attainment of $Y_{\text {DLk }}=1$ condition, in the case of a set of timehistories scaled to increasing values of IM.

Finally, the PBA is completed through the verification step (Fig. 11.1g) by computing, through the hazard curve obtained from the PSHA, the annual rate of exceedance $\lambda_{\mathrm{PLk}}$ of the earthquake correspondent to the given performance (or its return period $\left.\mathrm{T}_{\mathrm{R}, \mathrm{PLk}} \approx 1 / \lambda_{\mathrm{PLk}}\right)$. Finally, this value is compared with the target earthquake hazard level $\left(\bar{T}_{R, P L k} \approx 1 / \bar{\lambda}_{P L k}\right)$ in order to establish if rehabilitation interventions are necessary or not. 


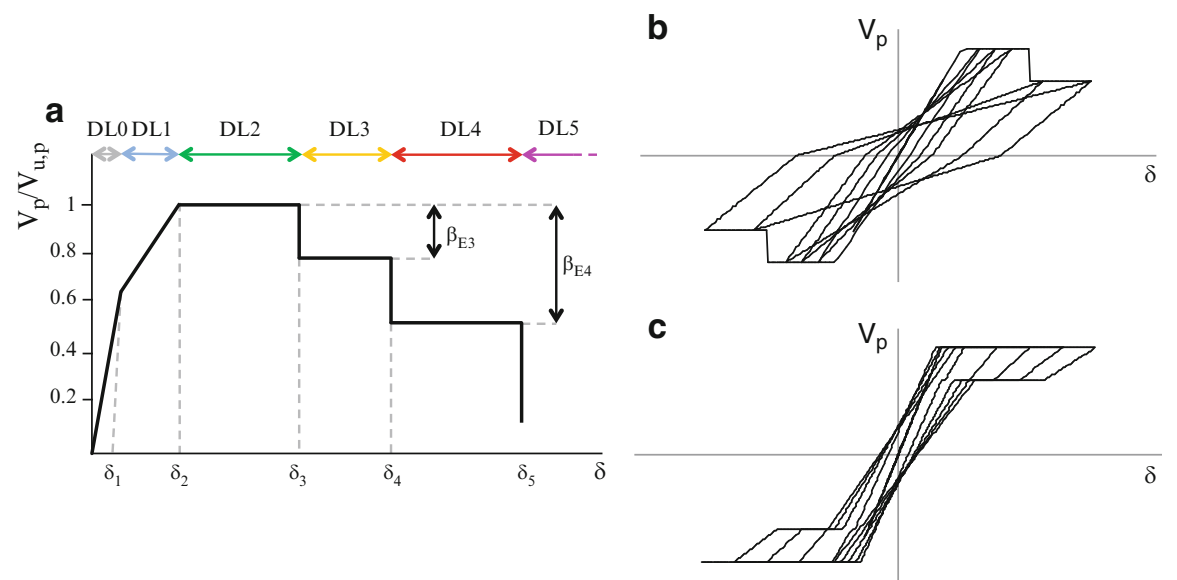

Fig. 11.2 Backbone of a masonry panel based on a multilinear constitutive law (Adapted from Cattari and Lagomarsino (2013)) (a) and sketch of some typical hysteretic responses of masonry piers subjected to a prevailing shear (b) and flexural (c) failure mode

\subsection{Pros and Cons of Nonlinear Static and Dynamic Analyses}

The main advantages of NLDA are the following. Since it models the dynamic behavior of the structure, this is the more accurate method for the simulation of the phenomenon. Indeed, the contribution of all modes is implicitly considered, as well as the effect of vertical component of the input motion, sometimes not negligible. Moreover, this method does not need the conventional transformation to an equivalent nonlinear single degree of freedom system, since the seismic demand, described in terms of acceleration time history, is directly involved in the analysis; on the contrary, pushover analysis does not consider the seismic input and the displacement demand is evaluated a posteriori by the ADRS.

Despite such evident pros, the higher computational effort and some additional modeling features limited the feasibility of the method in the engineering practice; moreover, there are some critical procedural aspects related to the PBA. As regards the modeling features, it is evident the reliability of the dynamic method is conditioned from the accuracy of the constitutive laws adopted for describing the nonlinear cyclic hysteretic response of masonry panels (Fig. 11.2b), while for pushover analysis only the backbone curve (Fig. 11.2a - in terms of normalized shear strength of panel $\mathrm{V}_{\mathrm{p}} / \mathrm{V}_{\mathrm{u}, \mathrm{p}}$ and drift $\delta$ ) is need. As testified by numerous experimental tests on masonry panels, the cyclic hysteretic description must be able as much as possible to capture the differences in the various failure modes that may occur (rocking, diagonal cracking, sliding) and in the response of piers and spandrels. 
As regards the PBA procedural aspects, first of all it is useful to point out that the application of an acceleration time history at the base of the structure and the evaluation of its nonlinear dynamic response produce a large amount of results: time histories of nodal displacements, element drifts, local and global energy dissipation. These data give a comprehensive picture of the building response and can be properly processed in order to assess if a given PL has been attained or not. However, this is not a simple task and many alternative approaches have been proposed in the past, usually referred to the definition of a global damage index that is well correlated with the DLs. A review of several proposed damage indexes is made in Williams and Sexsmith (1995), being most of them related to reinforced concrete structures, except one proposal for masonry ones (Benedetti et al. 2001) and critical disquisitions by some authors (e.g. Tomazevic 1999). Apart from the definition of damage indexes, recently in Mouyiannou et al. (2014) specific criteria to define PLs from the execution of NLDA have been proposed. However, none of these proposals have been yet implemented in the PBA procedures proposed by codes and recommendations. Indeed, at code level, the common trend is to adopt as reference result of the NLDA the maximum displacement occurred in the structure: thus, to proceed to the verification, it is usually compared with the displacement capacity obtained by the nonlinear static procedure, with the related criteria. It is evident that this use is very simplistic respect to the potentials of such an accurate method. Finally, the proper selection of time history represents a critical issue: on the one hand, the admissibility of scaling records is debated in literature; on the other hand, in the case of cloud method adoption, it is necessary to have a sufficient number of records to apply the MSA, in particular characterized by values of IM which produce a seismic demand very close to the attainment of the given PL (Jalayer and Cornell 2009).

Passing to the NLSA, despite some intrinsic limitations of the static approach, which can be inferred from the first sentence of this section, it represents a quite effective and feasible tool for the PBA of existing masonry buildings, being nowadays widespread not only at research level but also in the engineering practice.

As regard modeling, NLSA requires only the simulation of the monotonic behavior of masonry panels; this makes the formulation and definition of mechanical parameters easier than in case of NLDA. Many nonlinear models have been proposed for the simulation of the in-plane response of masonry panels; the most simple option for the implementation in the equivalent frame approach is the use of a nonlinear beam model, that presents the following main advantages: (i) it is particularly easy to be implemented also in practice-oriented software packages; (ii) it is consistent with the recommendations included in several seismic codes ASCE 41-13 2014; EC8-Part 3 2005); (iii) it is based on few mechanical parameters that may be easily defined and related to in-situ tests. Concerning this, despite the more spread adoption of a simple bilinear law, the increasing requirement to verify also PLs close to the Near Collapse condition makes pressing the adoption of more refined constitutive laws, like as those based on a multilinear backbone curve (Fig. 11.2a). 

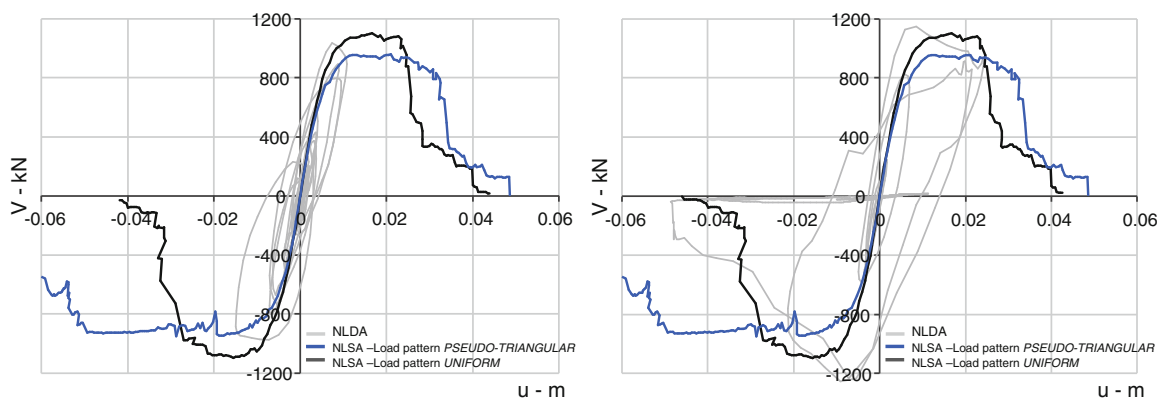

Fig. 11.3 Comparison between backbone obtained by the execution of a NLSA and the results of NLDA achieved by using a seismic input scaled for two different levels of IM

As regards the computational aspects, the execution of pushover analysis requires proper choices concerning: (i) seismic load pattern; (ii) selection of control node (to optimize the numerical convergence); (iii) representative displacement to be considered in the pushover curve. All of them affect the resulting pushover curve, in particular for irregular buildings and in presence of flexible diaphragms.

Regarding load pattern (i), that aims to simulate the seismic action through static incremental horizontal forces, possible options are (Aydinoglu and Onem 2010): (1) proportional to masses (obtained from a uniform displacement shape); (2) proportional to the fundamental modal shape (modal); (3) given by a proper combination of different modes (SRSS-based); (4) obtained from a triangular displacement shape (pseudo-triangular); (5) load pattern adapted to the current displacement shape (adaptive). Indeed, the pushover curve aims to represent the backbone achieved by the virtual application of a seismic input with increasing intensity level: to this aim, the comparison with results of NLDA could be very useful to select the most correct load pattern to be adopted (Fig. 11.3).

Usually codes propose to assume at least two patterns, because the inertial force distribution changes, with the occurrence of damage, from an initial modal distribution to patterns that are proportional to the deformed shape, which often at collapse is closer to the uniform one (in the case of a soft storey mechanism at the base). An alternative is the adaptive pushover, in which at each step of the analysis the load pattern is updated as a function of the evolution of the nonlinear response of the structure (Antoniou and Pinho 2004; Chopra et al. 2004; Gupta and Kunnath 2000). However, very few applications to masonry structures can be found in the literature (Galasco et al. 2006), due to their distinctive features, such as the softening response of masonry under shear and the presence of flexible floors.

The modal pattern is not reliable in the case of flexible horizontal diaphragms, because each mode mainly involves the local behavior of single walls, having a very low fraction of the participating mass. Thus, in order to reach a significant total mass participation, a SRSS-based load pattern can be defined, in a given direction, by considering the first $\mathrm{N}_{\mathrm{r}}$ modes that, in each wall, are characterized by the same sign of displacements at different levels; if the resulting participating mass is still 
lower than $75 \%$, this percentage should be anyhow considered in the conversion to the equivalent SDOF system. If the building is regular in elevation, a simpler alternative is the use of a pseudo-triangular load pattern, because it assures that the seismic masses in all parts of the building are involved in the pushover analysis.

An advanced approach, in order to treat the complex configurations (flexible floors, irregularity in plan and in elevation), is the multi-modal pushover analysis (Chopra and Goel 2002), which can also combine, if necessary, the effect of both components of the input motion (Reyes and Chopra 2011), instead of considering them as independent.

The choice of control node (ii), both in elevation and plan, is important in order to optimize the convergence of the nonlinear pushover analysis. Regarding the elevation, it is suggested to select the control node above the level in which the collapse occurs. For this reason, codes commonly propose to assume the control node at the top floor. Regarding the in-plan location, the choice represents a very crucial issue in case of existing buildings with timber floors or vaults. In fact, while in the case of rigid floors the results are almost insensitive to the position of the control node, in the case of flexible ones they strongly depend on it, because of the different stiffness and strength of masonry walls. The numerical results are more accurate if the control node is selected in the wall that collapses as the first.

The selection of the representative displacement for the pushover curve (iii) is a crucial point for the conversion into capacity curve when diaphragms are not rigid and/or the building is irregular in plan. In fact, the capacity curve shows very different displacement capacity (ductility) whether the considered displacement is that of a wall that reaches failure or not. Thus, instead of the displacement of the control node, it is preferable to use the average displacement of all nodes at the same level, weighted by the seismic nodal mass. This procedure represents a heuristic approach useful to get an unambiguous outcome, which has also a physical interpretation: indeed, the displacement-based approach considers the capacity of seismic masses to move, in comparison with the earthquake displacement demand.

Once obtained the pushover curve, the PBA requires the adoption of a proper nonlinear static procedure. Various proposals are available in the literature, like as the Capacity Spectrum Method (CSM) and Displacement-Based Method (DBM) (Freeman 1998; Calvi 1999; Priestley et al. 2007), the Coefficient Method (CM) (ASCE 41-13 2014) and the N2 Method (Fajfar 2000). All of them basically require the introduction of some conventional approaches: (i) to convert the original MDOF model into the equivalent SDOF system, to be compared with the seismic input (ADRS); (ii) to reduce the elastic spectra in order to take into account the increasing of dissipation due to the nonlinear structural behavior. As regard the conversion, it is usually based on a transformation factor computed as a function of displacement shape vector, assumed consistent with the fundamental modal shape of the system (Fajfar 2000). As regard the reduction, two approaches are proposed: overdamped spectra (adopted by CSM, DBM, CM methods), in which an equivalent linear model is considered with a properly increased viscous damping, and inelastic spectra (N2 method), which are defined in terms of ductility (only in this 
case it is necessary to proceed to a further conversion in a bilinear capacity curve, in order to define the initial equivalent period and the ductility). After a wide set of dynamic parametric analyses on different nonlinear hysteretic SDOF models, some refinements of the CSM have been proposed as Modified ADRS (MADRS) method (FEMA 440 2005), in order to obtain from static nonlinear analysis a displacement demand as much as possible equal to the one obtained from nonlinear dynamic analyses; more recently, further improvements on such direction have been proposed just for masonry buildings (Graziotti et al. 2013). However, an agreement on the most reliable method still represents an open issue.

\subsection{Use of Proper Orthogonal Decomposition (POD) for the PBA}

One of most critical issue related to the use of NLDA is the availability of effective tools and procedures to properly exploit the large amount of results produced.

To this aim, the use of the Proper Orthogonal Decomposition (POD - Lumley 1970) is proposed for the first time, as far as the Authors know, in the field of seismic assessment; this method is also known as Principal Component Analysis (PCA), in the discrete-space context, or as Karhunen-Loeve Expansion (KLE Loeve 1945; Karhunen 1946), when used in the context of continuous second-order stochastic processes. Main aim of the POD is to represent, through a non-parametric modal expansion, a random process as a linear combination of deterministic quantities, called modes, modulated by random uncorrelated coefficients called Principal Components (PCs). The modal representation offered by POD is the best in the mean square sense (i.e. energetic), because has the fastest possible convergence among all the possible linear combinations: this means that only some (usually a few) terms of the series are really needed to capture the relevant energetic part of the observed phenomenon. Geometrically, the aim of POD is to find a rotation of the reference system that minimizes the covariance (i.e. the redundancy) of the random variables, maximizing the variance (i.e. the information) of the new variables in the new reference system. The change in basis can be seen as a change of the point of view that improves the "visible" information included in the dataset.

In the past it has been already applied in many other fields, like as economics (Falco et al. 2006) or other engineering applications (Berkooz et al. 1993; Han and Feeny 2003; Solari et al. 2007; Marrè Brunenghi 2014). Herein, the use of the POD is proposed in order to interpret the dynamic structural response to an earthquake excitation, from the results of numerical simulations by NLDA or experimental tests on shaking table, in terms of dominant behaviours. This approach is more effective than referring to single and instantaneous peaks of the response (e.g. the maximum displacement occurred in a point of the structure, like as the top level). Moreover, it could be very useful also to preliminary correct data from 
measurements errors or noise, in case of experimental test, or from slight convergence errors, in case of numerical simulations.

The method basically consists in the eigenvalue decomposition of the covariance matrix estimated from the data. Starting from the original dataset, POD aims to find a new set of coordinates in such a way that the first PC has the maximum variance and each succeeding component has the highest variance possible under the constrain that it is orthogonal to the preceding component: in this way the PCs are mutually uncorrelated.

First step to apply this technique consists in arranging the results $\mathbf{q}(\mathrm{t})$ of the NLDA in a data matrix $\mathbf{V}$, whose columns contain the signal time histories (in such a way that each line displays the variables observed at the same time). Then the matrix $\mathbf{V}$ is decomposed through a basis of orthonormal vectors $(\boldsymbol{\phi})$ in order to obtain a new matrix whose components are uncorrelated:

$$
V=\sum_{k=1}^{N} \phi_{k}\left(\phi_{k}^{T} V\right)=\sum_{k=1}^{N} \phi_{k} Y_{k}
$$

The components $\mathrm{Y}_{\mathrm{k}}$ of $\mathbf{V}$ on the basis $\phi$ represent the principal components (PCs). The optimal basis to decompose $\mathbf{V}$ is represented by the covariance matrix C:

$$
\boldsymbol{C}=E\left[\boldsymbol{q}^{T} \boldsymbol{q}\right]=\left[\begin{array}{ccc}
\sigma_{q_{1}}^{2} & \cdots & C_{q_{1} q_{N}} \\
\vdots & \ddots & \vdots \\
C_{q_{1} q_{N}} & \cdots & \sigma_{q N}^{2}
\end{array}\right]
$$

The diagonal of $\mathbf{C}$ collects the variances of each signal time history, while the other elements are the covariances of all possible pairs of time histories.

The covariance matrix satisfies some relevant properties, that is to be symmetric and positive definite. Thus the eigenvalues are real and positive, the relative eigenvectors are real and can always be chosen so that they are mutually orthonormal.

Such eigenvalue problem is mathematically formulated as:

$$
(\boldsymbol{C}-\lambda \boldsymbol{I}) \phi=0
$$

where $\phi$ are the eigenvectors and $\lambda$ the eigenvalues, that is the variances of the Y rotated components, aimed to quantify the energy associated to each mode. Thus, the principal directions of the process can be obtained by solving such problem.

By sorting the eigenvalues in decreasing order it is possible to identify the dominant modes of the phenomenon.

According to the context in which the POD is herein proposed, the result $\mathbf{q}$ may be represented for example by the displacement or acceleration time histories of all nodes of the equivalent frame model (Fig. 11.4). 


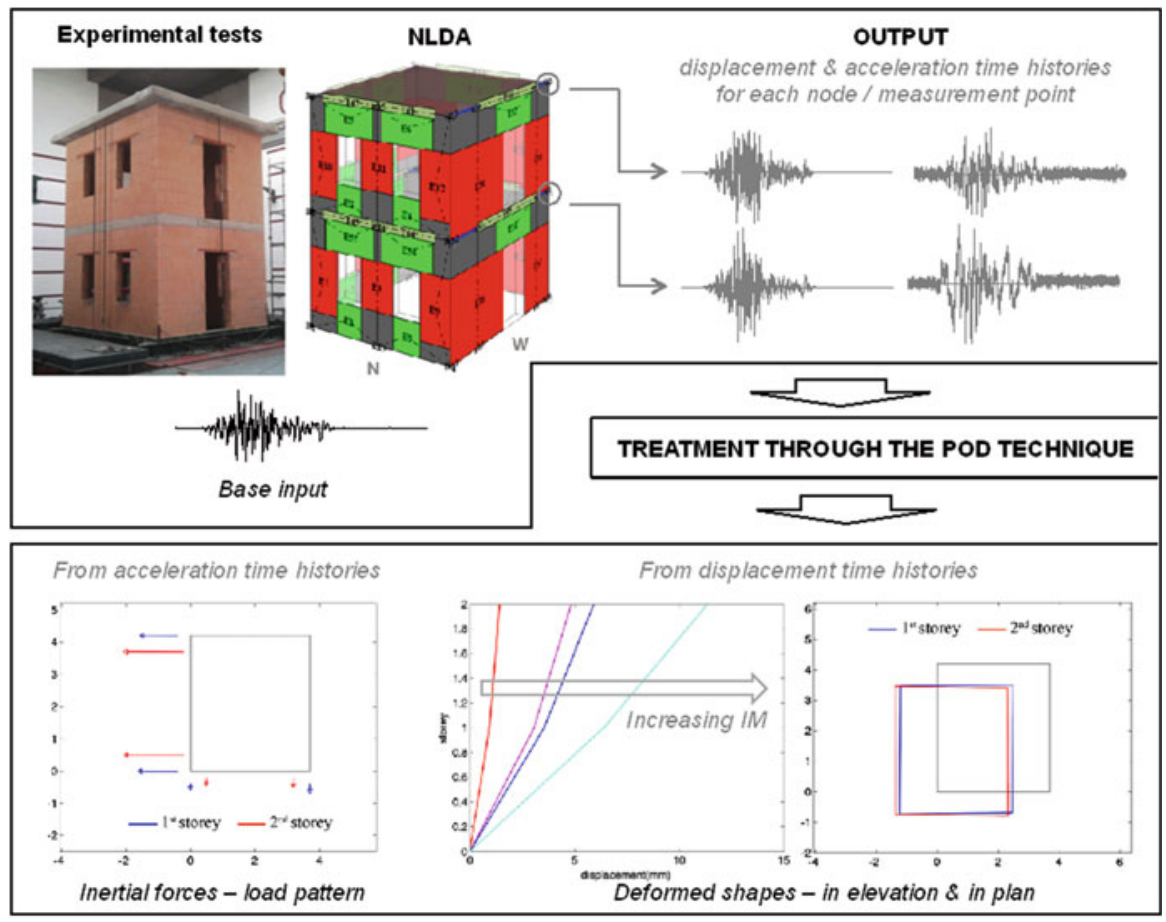

Fig. 11.4 Sketch on the use of POD technique to process data from experimental tests or NLDA results (Data adapted from Cattari et al. (2014))

The application to displacement time histories may support the definition of deformed shapes both in plan and in elevation, while if POD is applied to nodal accelerations the dominant distribution of inertial forces transmitted to the structure can be estimated. This latter application may be very useful to calibrate the load pattern distribution to be adopted in pushover analyses; in particular, if this evaluation is made on the results of IDA analyses, the relevance of considering an adaptive pushover analysis can be assessed. Moreover, in $\S 11.5$ the use of POD is also proposed to process data useful to the definition of the PLs according to the multiscale approach, in the case of NLDA.

In Cattari et al. (2014) an application of the POD technique is proposed for the interpretation of shaking-table tests made on two prototypes of two-storey masonry buildings: results include both the analysis of experimental tests measurements and the processing of results from a numerical simulation through NLDA performed by the equivalent frame program Tremuri (Lagomarsino et al. 2013). The POD technique turned out to be very useful and effective. 


\subsection{Multiscale Approach for the Definition of PLs Thresholds}

The definition of DLs thresholds of the EDP (useful to check the fulfillment of corresponding PLs) from NLSA, as well as NLDA, is a complex task.

In the case of existing reinforced concrete buildings, nonlinear elements used for columns and beams are usually elasto-plastic, without strength degradation. Therefore, the pushover curve that is obtained do not present any strength degradation and the verification of PLs is made at the level of single elements, considering: for Damage Limitation PL the occurrence of a given threshold in the first element; while for Near Collapse PL another threshold at element scale which is checked on a combination of elements which give rise to a predefined collapse mechanism (e.g. column sway or beam sway).

In the case of complex historical masonry buildings nonlinear constitutive laws for piers and spandrels take into account strength degradation; this allows to obtain, from the pushover analysis with an equivalent frame model, a capacity curve that shows not only the stiffness degradation and the maximum strength, but also the strength degradation for high values of the displacement demand. For this reason some codes (e.g. EC8 Part 3 2005) define PLs directly on the pushover curve and require a verification directly in terms of displacement demand and capacity, without the a posteriori verification of each masonry element. This approach is not enough accurate in the case of complex masonry buildings with flexible diaphragms and/or big and irregular plan configurations. Indeed in these cases, as far as Near Collapse PL is considered, a significant damage in one single wall may not appear evident in the pushover curve of the whole structure in terms of strength decay. Analogously, for the detection of Damage Limitation PL, it is correct to allow a given damage in some elements, if the global stiffness degradation is still limited and the maximum strength is not reached, but it is not acceptable that damage of structural elements spread too much in the building, even if there is not any tangible effect in the global pushover curve. However, in the case of complex masonry buildings, for Near Collapse PL the a priori selection of predefined failure mechanisms would be quite difficult, due to the possible irregular topology of the equivalent frames, while for Damage Limitation PL the adoption of a structural element approach, based on the checking of the first damaged structural element, would be too conservative.

In Mouyiannou et al. (2014), specific criteria for defining PLs in case of masonry buildings through nonlinear dynamic analyses have been recently proposed. They combine various approaches and variables differentiated as a function of increasing levels of damage severity (until DL3). In case of DL1 (corresponding to Immediate Occupancy PL), the Authors suggest to adopt the displacement associated to the first pier reaching its maximum shear resistance. In case of DL2 (related to Damage Limitation PL) and DL3 (related to Life Safety PL), they tested the use of three different criteria, mainly based on: (i) the global lateral strength evolution (in terms of attainment of the maximum base shear or a $20 \%$ strength degradation); (ii) the 
damage diffusion (in terms of percentage of piers area failing); (iii) the degradation of the structural response for increasing levels of the ground motion (monitored through fixed changes in the slope of the IDA curves represented in terms of PGA drift). Then, after the analysis of results achieved on some prototype buildings (two or three storey buildings, with almost rigid floors and compact plan configurations), the Authors suggested the adoption of criterion i), as that most stable with the record-to-record variability, by expressing the attainment of such DLs in terms of average weighted story drift (DL2) and maximum interstory drift (DL3). Such criteria are basically coherent also with those suggested in some code (Eurocode 8 - Part 3) in the case of nonlinear static analyses.

However, in particular when horizontal diaphragms are flexible, the adoption of a single criterion seems to be unreliable to detect all possible failure mechanisms. To overcome this problem a multiscale approach for defining DLs in case of historical masonry building was proposed by PERPETUATE project, focused on the assessment of monumental architectural assets (Lagomarsino and Cattari 2015). It aims to combine in an integrated way different criteria and checks at various scales, which are relevant for the seismic response of the building: structural elements scale (local damage, E), architectural elements scale (damage in macroelements, M) and global scale (G). According to this criterion, a coherent approach is applied to define the DLs in case of both NLSA, where the EDP is represented by the displacement $u$ on the pushover curve, and NLDA, where the EPD is constituted by the scalar variable $Y$ introduced in $\S 11.2$.

In the case of NLSA, since the final seismic assessment is made through the global pushover curve, the displacement corresponding to attaining DLk $(\mathrm{k}=1, \ldots, 4)$ is computed as:

$$
u_{D L k}=\min \left(u_{E, D L k} ; u_{M, D L k} ; u_{G, D L k}\right) \quad k=1, \ldots, 4
$$

where $u_{E, D L k}, u_{M, D L k}$, and $u_{G, D L k}$ are the displacements on the pushover curve corresponding to the reaching, respectively, of predefined limit conditions at these scales: element (E, piers or spandrels), macroelement (M, each masonry wall and, eventually, horizontal diaphragms) and global (G, pushover curve).

At global scale, the variable chosen to monitor the attainment of $u_{G, D L k}$ is the rate $\kappa_{G}$ of the total base shear over the maximum base shear of the pushover curve $\left(\kappa_{G}=V / V_{\max }\right)$; proper thresholds $\left(\kappa_{D L k}\right)$ are defined for DL1 and DL2 in the growing branch of the curve while DL3 and DL4 are located on the descending one.

At macroelement scale, the following variables are adopted: in the case of masonry walls, the interstorey drift $\theta_{w, l}$ by any wall and level $\left(w=1, \ldots, N_{w}-\right.$ wall number; $l=1, \ldots, N_{l}-$ level number) must not reach the threshold $\theta_{D L k}$; in case of diaphragms, the angular strain $\gamma_{q, l}\left(q=1, \ldots, N_{q}\right.$ - diaphragm number) must not reach the threshold $\gamma_{D L k}$. It is worth noting that usually the interstorey drift is computed referring to the horizontal displacements at floor levels, but this is correct only in the case of strong spandrels (shear-type behaviour). More in general, the interstorey drift of wall $\theta_{w, l}$ has to be evaluated by taking into account the 
contribution of both horizontal displacement and rotation of nodes, for example according to:

$$
\theta_{w, l}=\frac{\bar{u}_{w, l}-\bar{u}_{w, l-1}}{h_{l}}+\frac{\bar{\varphi}_{w, l}+\bar{\varphi}_{w, l-1}}{2}
$$

where: $h_{l}$ is the interstorey height at level $l$, while $\bar{u}_{w, l}\left(\bar{u}_{w, l-1}\right)$ and $\bar{\varphi}_{w, l}\left(\bar{\varphi}_{w, l-1}\right)$ are the average horizontal displacement and rotation of nodes located at level $l$ (or $l-1$ ) in wall $w$ (positive if counterclockwise).

Finally, at element scale the cumulative rate of panels that reach a certain DLi (piers $-\Lambda_{P, D L k}-$ and spandrels $-\Lambda_{S, D L k}$ ) is introduced to check for the attainment of $\mathrm{u}_{E, D L k}$. To this aim, proper constitutive laws (e.g. Cattari and Lagomarsino 2013) must be defined for these structural elements (Fig. 11.2a), possibly considering the strength degradation, and able to detect the attainment of progressing DLs, for example by checking the reaching of given drift limits $\delta_{D L i}$ (being the damage levels DLi at element scale defined for $i$ from 1 to 5).

The cumulative rate of damage $\Lambda_{S, D L k}$ is defined as the percentage of spandrels that reached or exceeded a given DLi (checked through the given drift thresholds $\left.\delta_{D L i}\right)$ :

$$
\Lambda_{S, D L k}=\frac{1}{N_{S}} \sum_{S} H\left(\frac{\delta_{s}}{\delta_{D L i}}-1\right) \quad i=k+2
$$

where the sum is extended to the total number of spandrels $\left(\mathrm{s}=1, \ldots, N_{S}\right)$ in the building and $H$ is the Heaviside function (equal to 0 until the demand $\delta_{s}$ in the s-th spandrel does not reach the capacity $\delta_{D L i}$ ).

The cumulative rate of damage $\Lambda_{P, D L k}$ is defined as the percentage of piers that reached or exceeded a given $\mathrm{DLi}$, weighted on the corresponding cross section $A_{p}$ :

$$
\Lambda_{P, D L k}=\frac{\sum_{P} A_{p} H\left(\frac{\delta_{p}}{\delta_{D L i}}-1\right)}{\sum_{P} A_{p}} \quad i=k+1
$$

where the sum is extended to the total number of piers $\left(\mathrm{p}=1, \ldots, N_{P}\right)$.

It is worth noting that, according to Eqs. (11.6) and (11.7), a higher damage level is accepted in spandrels than in piers. For example, to check the attainment of DL2 $(\mathrm{k}=2)$ the reaching of damage levels $3(\mathrm{i}=\mathrm{k}+1)$ and $4(\mathrm{i}=\mathrm{k}+2)$ are checked at the scale of pier and spandrel elements, respectively. In case of DL4, only attainment of damage level 5 in piers is considered. This assumption reflects the different hierarchic role of these elements in the behavior of masonry walls. In fact, piers represent the most important elements, which bear both static loads and seismic action, whereas spandrels are secondary elements, which connect piers by transmitting bending moments. 
Table 11.1 proposes ranges of possible values to be used for checks at the different scales; of course these thresholds could be validated or updated by further experimental tests or evidence from observed damage. At local scale, a unique value $\Lambda_{P-S}$ is proposed as threshold for cumulative rate variables $\Lambda_{P, D L k}$ and $\Lambda_{S, D L k}$ for both piers and spandrels and all DLk; it allows that damage spreads in a limited percentage of elements, but avoids that the DLk is reached due to just one single element. The expression herein proposed has been calibrated through an extensive application of the multiscale approach to several buildings, by considering various irregularities and diaphragms of different stiffness (Cattari and Lagomarsino 2013). In particular, the proposed threshold takes into account the damage induced by the application of the gravity loads $\left(\Lambda_{P(s), D L k, O}\right)$ and the number of pier and spandrels in the given building. At macroelement scale, interstorey drift limits may be selected within given ranges, which are compatible with values proposed in Calvi (1999). At global scale, range of values for the thresholds of the rate of the maximum overall base shear are compatible with provisions of Eurocode 8, Part 3 (EN 2005); in the case of DL1, a lower bound is defined in order to avoid the occurrence of a slight Damage State in the very beginning of the growing branch of the capacity curve. In some cases, additional checks at macroelement scale (e.g. for horizontal diaphragms) or local scale (e.g. by monitoring the damage is some relevant elements) should be considered for specific performance requirements (e.g. related to the safety of people).

Figure 11.5 illustrates synthetically the steps to be followed in the case of NLSA for the definition of DLk on the pushover curve, by the multiscale approach.

In the case of NLDA, in order to be compatible as much as possible with the multiscale approach defined for NLSA, the scalar variable $Y_{D L k}$ for a given nonlinear dynamic analysis is introduced as:

$$
Y_{D L k}=\max \left(Y_{E, D L k} ; Y_{M, D L k} ; Y_{G, D L k}\right) \quad k=1, \ldots, 4
$$

where the scalar variables $Y_{E, D L k}, Y_{M, D L k}$, and $Y_{G, D L k}$ are computed as the ratio between the maximum value, attained during the time history, of the variables afore introduced at three different scales $\left(\mathrm{E}=\Lambda_{\mathrm{P}}, \Lambda_{\mathrm{S}} ; \mathrm{M}=\theta_{w, l}, \gamma_{q, l} ; \mathrm{G}=u\right)$ and the corresponding thresholds.

More specifically, $\mathrm{Y}_{\mathrm{DLk}}$ is computed as:

$$
Y_{D L k}=\max \left[\frac{\max \left(\Lambda_{P, D L k} ; \Lambda_{S, D L k}\right)}{\Lambda_{P-S}} ; \quad \max \left(\frac{\theta_{w, l}}{\theta_{D L k}} ; \frac{\gamma_{q, l}}{\gamma_{D L k}}\right) ; \quad \frac{u_{\max }}{u_{G, D L k}}\right]
$$

where the displacement $u$ is the same representative of the structural response selected in the case of NLSA. It is worth noting that in the case of DL1 the check at global scale could be performed also in terms of strength (with reference to the reaching of the thresold of $0.5 \mathrm{Vmax}$ ) than displacement capacity. Figure 11.6 summarizes the application of the multiscale approach in the case of results from 


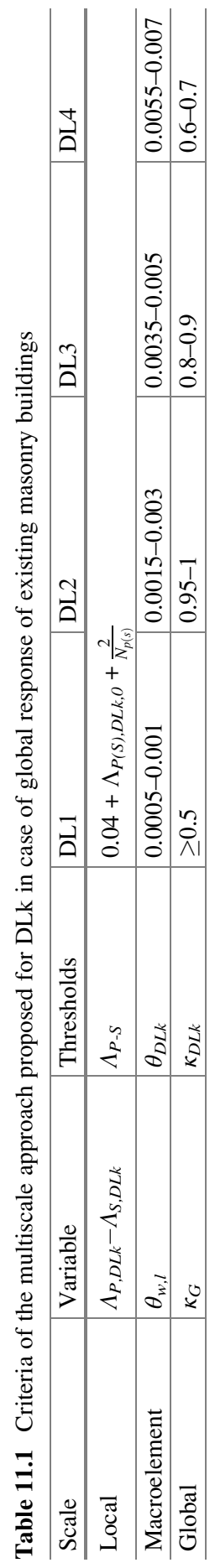




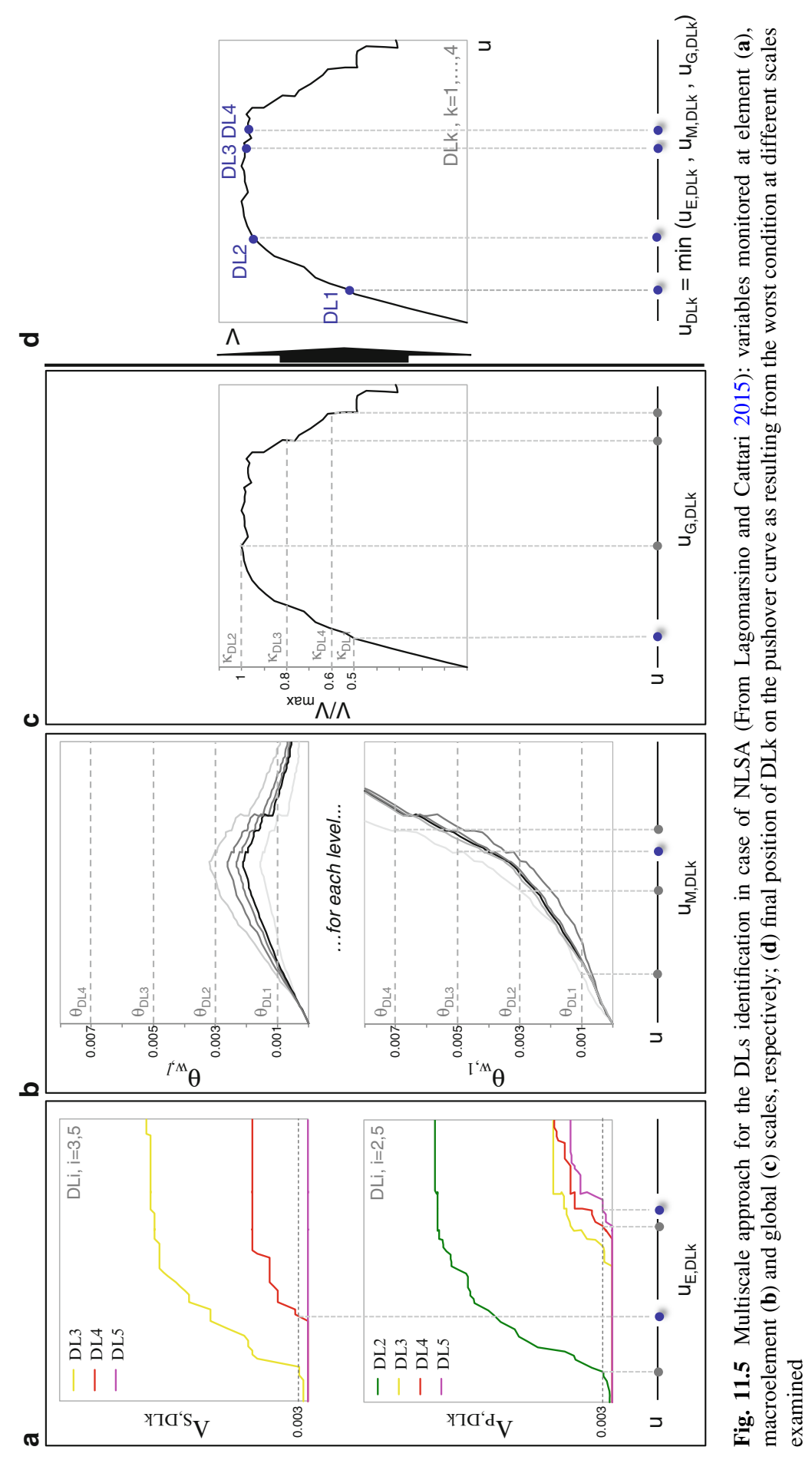




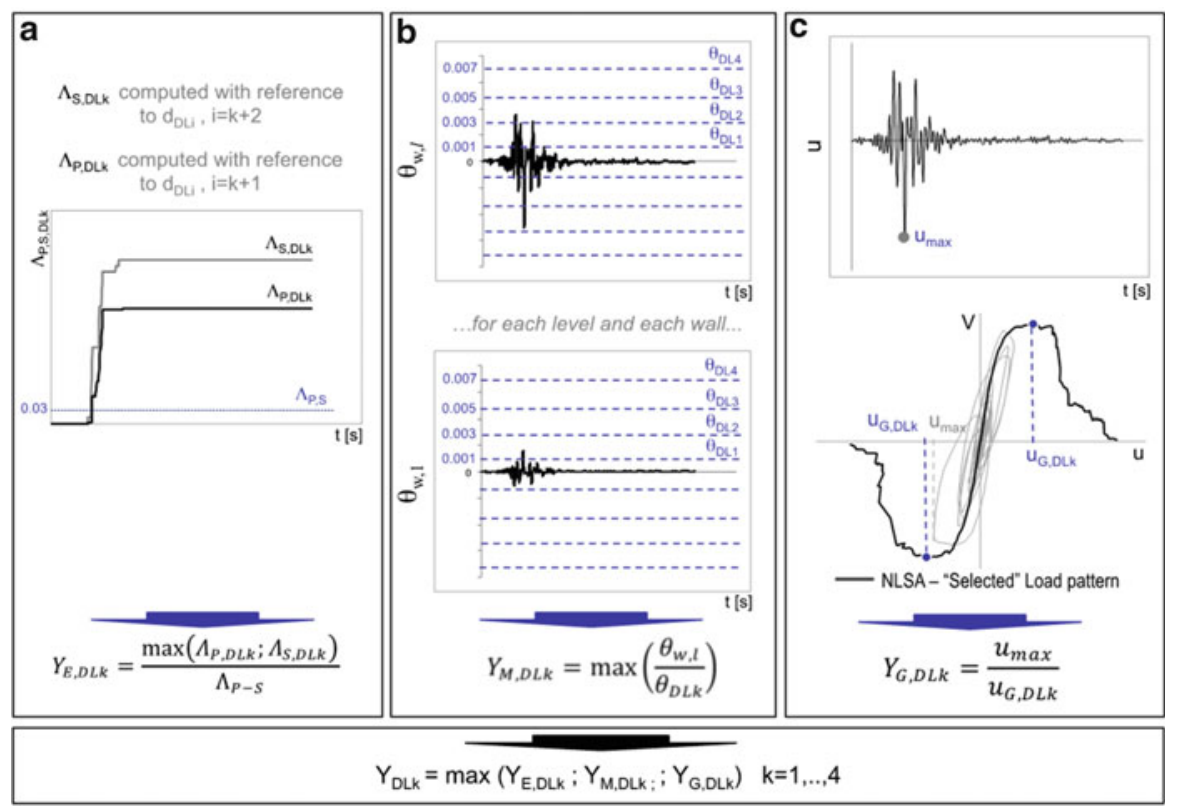

Fig. 11.6 Multiscale approach for the DLs identification in case of NLDA (for a given time history as scaled to a given intensity measure, in the case of IDA method). (a) Element scale. (b) Macroelement scale. (c) Global scale

a single NLDA (that is, for a given time history, scaled to a given intensity measure, in the case of IDA method). Of course results of all analyses have to be properly processed: it is assumed the attainment of $Y_{D L k}=1$ indicates the reaching of the examined DL. The threshold $u_{G, D L K}$ (computed according to the criteria adopted at global scale in case of NLSA) is obtained for example by considering the pushover curve resulting from the adoption of the most correct load pattern, as selected through a preliminary comparison with the results of NLDA; as introduced in $\S 11.4$, to this aim the application of the POD technique to the acceleration time histories turns out to be very useful.

In the case of checks performed at global scale, it is worth to point out that the maximum displacement $u_{\max }$ at top level could be affected by single peaks of the response, due to the contribution of higher modes or even to numerical convergence problems. In order to be coherent with the displacement $u_{G, D L K}$, obtained by the NLSA, it is suggested to use the displacement time history $(u)$ preliminary treated by the application of the POD technique by considering as vector $q$ (see Eq. 11.2) the weighted average displacement at all levels of the building $\left(\mathrm{N}_{1}\right)$. 
a
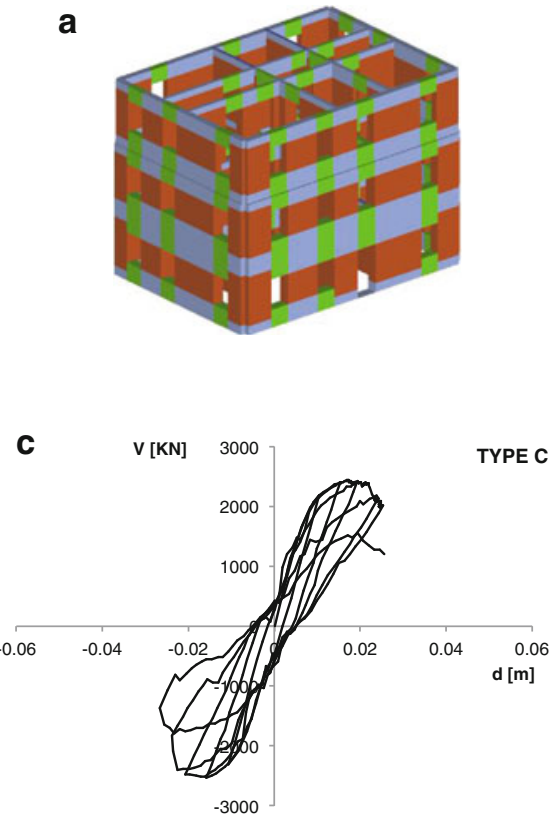

b

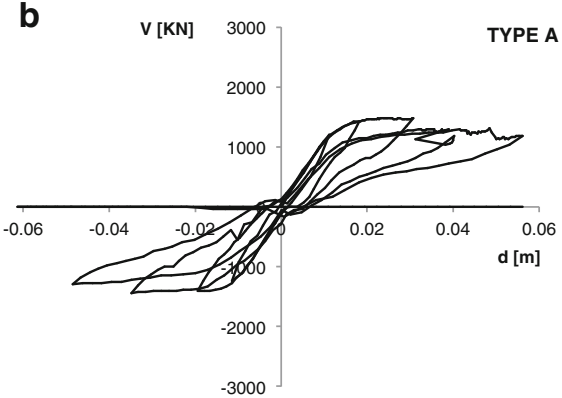

d

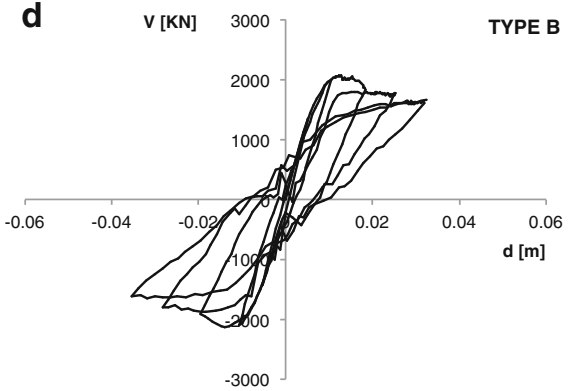

Fig. 11.7 Results of cyclic pushover analyses on a three storey URM masonry building as a function of different structural details (From Cattari and Lagomarsino 2013): (a) 3D view of Equivalent Frame model; (b) Type A - representative of Weak Spandrel-Strong Pier failure mode (with very weak spandrels, without tensile resistant elements coupled and poor interlocking); (c) Type C - representative of Strong Spandrel-Weak Pier (soft storey) failure mode (with reinforced concrete elements coupled to spandrels); (d) Type B - intermediate failure mode (with spandrels characterized by a good interlocking)

\subsection{Computation of the Seismic Input Compatible with Each PL}

In case of NLSA, the method herein adopted as basic reference is the classical CSM which uses overdamped spectra. If the seismic input is given, the evaluation of the displacement demand requires an iterative procedure. On the contrary, the evaluation of the seismic input that produces a given displacement (that is the adopted outcome of the assessment, $\mathrm{IM}_{\mathrm{PL}}$ ) is straightforward, once the corresponding equivalent viscous damping $\left(\xi_{P L}\right)$ is known. This latter may be computed from cyclic pushover analyses or from analytical expressions proposed in literature for similar buildings (Calvi 1999; Priestley et al. 2007; Blandon and Priestley 2005; Sullivan and Calvi 2013). Recently in Cattari and Lagomarsino (2013) some expressions specifically calibrated for existing masonry buildings have been proposed on basis of cyclic pushover analyses on different configurations that exhibited various global failure mechanisms (i.e. soft storey or with damage spreads also in spandrels), directly related to specific structural details (e.g. the presence of reinforced concrete ring beams coupled to spandrels). Figure 11.7 

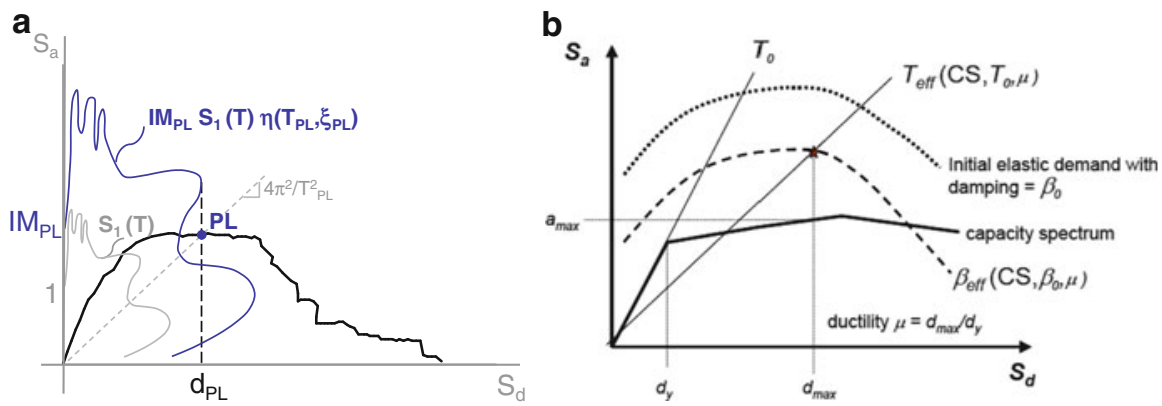

Fig. 11.8 (a) General CSM procedure proposed for the evaluation of IMPL; (b) MADRS procedure proposed in FEMA 440

summarizes some of results discussed more in detail in Cattari and Lagomarsino (2013) in the case of analyses performed on a three storey URM masonry building.

Once defined $\xi_{P L}$ and the corresponding period $\left(\mathrm{T}_{\mathrm{PL}}\right)$, if the ADRS is regular and the spectral displacement increases monotonically with the period $\mathrm{T}$ (or remains constant), $\mathrm{IM}_{\mathrm{PL}}$ can be simply evaluated as the IM for which the spectral displacement demand $S_{d}\left(T_{P L}, I M, \xi_{P L}\right)$ is equal to $\mathrm{d}_{\mathrm{PL}}$, being $\mathrm{d}$ the displacement of the capacity curve (that is the original displacement $u$ of the pushover curve properly converted in the SDOF system).

In order to extend the CSM application to the case of irregular ADRS (Fig. 11.8a), the following expression in proposed for the evaluation of $\mathrm{IM}_{\mathrm{PL}}$ :

$$
I M_{P L}=\frac{d_{P L}}{\max \left[S_{1}(T) \eta\left(T, \xi_{P L}\right) ; T_{D L 1}<T<T_{P L}\right]}
$$

where: $S_{1}(T)$ is the response spectrum normalized to IM and $\eta\left(T, \xi_{P L}\right)$ is the reduction factor applied to obtain the overdamped spectra, which may be assumed according to analytical expressions suggested in Eurocode 8 (2004) or in ASCE 41-13 (2014).

With respect to the original CSM, Eq. (11.10) aims to modify the evaluation of displacement demand with respect the classical direct intersection between reduced demand and capacity, taking into account the maximum displacement demand that the structure might have experienced from its elastic dynamic behavior until the reaching of the given $T_{P L}$. Such proposal has been supported by the results of an extensive set of nonlinear dynamic analyses on single blocks subjected to rocking failure (Lagomarsino 2015). This modification, that does not strictly use the secant period, is consistent also with the modification proposed by the MADRS method (FEMA 440 2005) that highlighted the need, on the basis of evidence from results of nonlinear dynamic analyses, to use for the definition of the equivalent linear SDOF system, values of the period and damping (called "effective") that are different from those associated to the secant ones in order to obtain more accurate results. (Fig. 11.8b). Then, the value of effective periods and damping are obtained through 


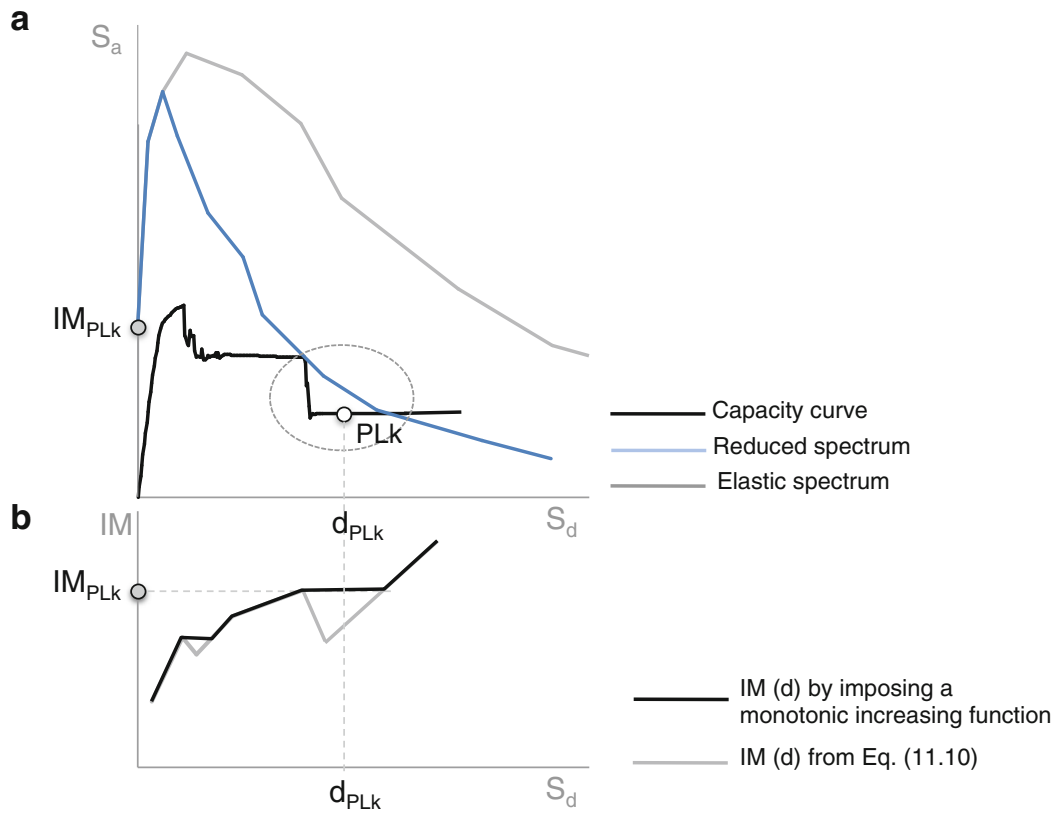

Fig. 11.9 CSM procedure proposed for the evaluation of $\mathrm{IM}_{\mathrm{PL}}$ in case of capacity curves characterized by sudden base shear decay

analytical expressions differentiated as a function of various possible hysteretic responses.

The proposal introduced by Eq. (11.10) is relevant in the case of irregular spectra, similar to the one of Fig. 11.8a, which are typical when obtained directly from a number of real records or by numerical models that evaluate soil amplification phenomena.

Finally a last comment concerning the use of Eq. (11.10) is related to the case in which the capacity curve presents brittle behaviors with a sudden strength degradation, quite common in case of masonry buildings. The Incremental Static Analysis (ISA) curve can be defined as the IM that causes a given displacement $d$ as a function of $d$; the application of Eq. (11.10) without additional restriction could provide a not strictly monotonic ISA curve, which should be inconsistent (because you cannot obtain a displacement demand with a value of IM lower than that which produces a lower displacement). Figure 11.9 shows such specific case, in the case of adoption of an analytical ADRS input (as that proposed in EC8 2004). In this case the IM is represented by the PGA; in Fig. 11.9b the grey line corresponds to the evaluation provided according to Eq. (11.10), the black one that consistent with the assumption of a monotonic increasing function. Moreover, Fig. 11.9a shows the comparison between the capacity curve and the overdamped spectrum, scaled to the $\mathrm{IM}_{\mathrm{PLk}}$ value; each point of the overdamped reduced spectra refers to the corresponding value of reduction compatible with the equivalent viscous damping 


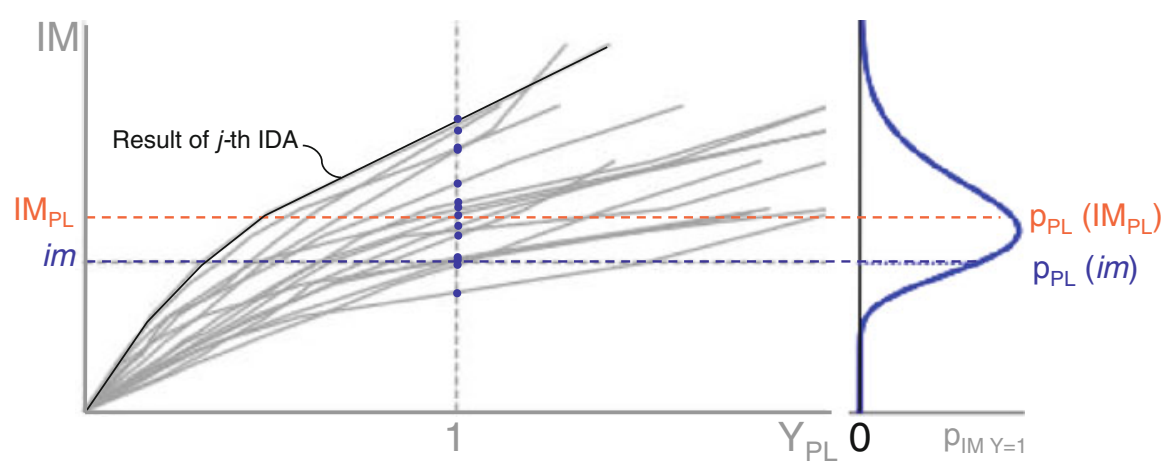

Fig. 11.10 Results of IDA and evaluation of $\mathrm{IM}_{\mathrm{PL}}$

on the capacity curve. From this figure it is evident that in the range marked by the dotted circle the adoption only of Eq. (11.10) would lead to inconsistent results.

Finally, in case of NLDA, the procedure is based on a statistical evaluation of $\mathrm{IM}_{\mathrm{PL}}$ through the Multiple Stripe Analysis (MSA), in the case of cloud method, or the IDA curves in correspondence of the attainment of $\mathrm{Y}_{\mathrm{DL}}=1$ condition, in the case of a set of time-histories scaled to increasing IM (Fig. 11.10).

\subsection{Conclusions}

A discussion on the use of nonlinear static and dynamic analyses for the Performance Based Assessment of masonry existing buildings is presented focusing the attention on structures dominated by a global behavior and reliably modeled through the equivalent frame approach. Some original contributions to strengthen the equivalence of criteria adopted in the two methods are proposed. In particular, such proposals deal with the definition of performance level thresholds for the structural capacity (to be adopted for checking the fulfillment of PLs) and the tools to enhance the use of rich amount of data carried out through nonlinear dynamic analyses.

As regard the first objective, a multiscale approach is introduced aimed to combine in an integrate way different criteria and checks at various scales which are relevant for the seismic response of the building (element, macroelement, global). This approach is needed for complex masonry buildings, in particular when horizontal diaphragms are flexible. PLs are defined through the introduction of proper variables, directly obtained by numerical models, in a consistent way in the case of static and dynamic methods.

As regard the second one, the use of the Proper Orthogonal Decomposition (POD) technique is proposed to detect the dominant behaviors highlighted by the structure when a nonlinear dynamic analysis or shaking table tests are performed, appearing this approach more effective than referring to single and instantaneous 
peaks of the response (more affected by random noise, due to numerical convergence problems or measurements errors). Beside interpreting the results in a more effective way, the processing of data through the POD technique is also useful to provide information on the correct deformed shape and load pattern to be adopted in the case of static procedures for verification.

Acknowledgments The research was funded by the national project ReLUIS-DPC 2014-2018 (www.reluis.it), supported by the Italian Civil Protection Agency, within the research thematic "Masonry buildings".

Open Access This chapter is distributed under the terms of the Creative Commons Attribution Noncommercial License, which permits any noncommercial use, distribution, and reproduction in any medium, provided the original author(s) and source are credited.

\section{References}

Antoniou S, Pinho R (2004) Development and verification of a displacement-based adaptive pushover procedure. J Earthq Eng 8(5):643-661

ASCE/SEI 41-13 (2014) Seismic evaluation and retrofit of existing buildings. American Society of Civil Engineers, Reston. ISBN 978-0-7844-7791-5

Aydinoglu MN, Onem G (2010) Evaluation of analysis procedures for seismic assessment and retrofit design. In: Garevsky M, Ansal A (eds) Earthquake engineering in Europe. Springer, Dordrecht, Netherlands, pp 171-198

Benedetti D, CArydis P, Limongelli MP (2001) Evaluation of the seismic response of masonry buildings based on energy functions. Earthq Eng Struct Dyn 30:1061-1081

Berkooz G, Holmes P, Lumley JL (1993) The proper orthogonal decomposition in the analysis of turbulent flows. Annu Rev Fluid Mech 25:539-575

Beyer K, Mangalathu S (2013) Review of existing strength models for spandrels. Bull Earthq Eng 11(2):521-542

Blandon CA, Priestley MJN (2005) Equivalent viscous damping equations for direct displacement based design. J Earthq Eng 9(Special Issue 2):257-278

Calderini C, Cattari S, Lagomarsino S (2009) In-plane strength of unreinforced masonry piers. Earthq Eng Struct Dyn 38(2):243-267

Calvi GM (1999) A displacement-based approach for vulnerability evaluation of classes of buildings. J Earthq Eng 3(3):411-438

Cattari S, Lagomarsino S (2013) Masonry structures, pp 151-200. In: Sullivan T, Calvi GM (eds) Developments in the field of displacement based seismic assessment. IUSS Press and EUCENTRE, Pavia, Italy, p 524, ISBN:978-88-6198-090-7

Cattari S, Degli Abbati S, Ferretti D, Lagomarsino S, Ottonelli D, Tralli A (2013) Damage assessment of fortresses after the 2012 Emilia earthquake (Italy). Bull Earthq Eng. doi:10. 1007/s10518-013-9520-x

Cattari S, Chioccariello A, Degée H, Doneaux C, Lagomarsino S, Mordant C (2014) Seismic assessment of masonry buildings from shaking table tests and nonlinear dynamic simulations by the Proper Orthogonal Decomposition (POD). In: Proceedings of the second European conference on earthquake engineering and seismology (ECEES), Istanbul, 25-29 Aug 2014

Chopra AK, Goel RK (2002) A modal pushover analysis procedure for estimating seismic demands for buildings. Earthq Eng Struct Dyn 31(3):561-582

Chopra AK, Goel RK, Chintanapakdee C (2004) Evaluation of a modified MPA procedure assuming higher modes as elastic to estimate seismic demands. Earthq Spectra 20(3):757-778 
CIB 335 (2010) Guide for the structural rehabilitation of heritage buildings, prepared by CIB commission W023 - Wall Structures, ISBN 978-90-6363-066-9

CNR-DT212 (2013) Recommendations for the probabilistic seismic assessment of existing buildings. Consiglio Nazionale delle Ricerche, Rome, Italy (in Italian). http://www.cnr.it/sitocnr/ IlCNR/Attivita/NormazioneeCertificazione/DT212.html

Coburn A, Spence R (2002) Earthquake protection. Wiley, Chichester, West Sussex, England. ISBN:978-0-470-84923-1

Douglas J, Seyedi DM, Ulrich T, Modaressi H, Foerster E, Pitilakis K, Pitilakis D, Karatzetzou A, Gazetas G, Garini E, Loli M (2015) Evaluation of the seismic hazard for the assessment of historical elements at risk: description of input and selection of intensity measures. Bull Earthq Eng 13. doi:10.1007/s10518-014-9606-0

EN 1998-1 (2004) Eurocode 8: design of structures for earthquake resistance - Part 1: General rules, seismic actions and rules for buildings. CEN (European Committee for Standardization), Brussels

EN 1998-3 (2005) Eurocode 8: design of structures for earthquake resistance - Part 3: Assessment and retrofitting of buildings. CEN (European Committee for Standardization), Brussels

Fajfar P (2000) A non linear analysis method for performance-based seismic design. Earthq Spectra 16(3):573-591

Falco A, Chinesta F, Gonzalez M (2006) Model reduction methods in option pricing. Instituto Valenciano de Investigaciones Economicas, Valencia, Spain

FEMA 440 (2005) Improvement of nonlinear static seismic analysis procedures. ATC, Washington, DC

Freeman SA (1998) The capacity spectrum method as a tool for seismic design. In: Proceedings of 11th European conference of earthquake engineering, Paris

Galasco A, Lagomarsino S, Penna A (2006) On the use of pushover analysis for existing masonry buildings. In: Proceedings of the 13th European conference on earthquake engineering, Geneva (CH), 3-8 Sept 2006, ID 1080

Graziotti F, Penna A, Magenes G (2013) Use of equivalent SDOF systems for the evaluation of the displacement demand for masonry buildings. Proceedings of VEESD, (p. Paper No. 347), Vienna

Grunthal G (1998) European Macroseismic Scale 1998: EMS-98, vol 15. Chaiers du Centre Européen de Géodynamique et de Séismologie, Luxembourg

Gupta B, Kunnath SK (2000) Adaptive spectra-based pushover procedure for seismic evaluation of structures. Earthq Spectra 16:367-392

Han S, Feeny B (2003) Application of proper orthogonal decomposition to structural vibration analysis. Mech Syst Signal Pr 17(5):989-1001

ICOMOS (2005) Recommendations for the analysis, conservation and structural restoration of architectural heritage. International Scientific Committee for Analysis and Restoration of Structures and Architectural Heritage (ISCARSAH), Document approved on 15/6/2005 in Barcelona

ISO 13822 (2010) Bases for design of structures - assessment of existing structures, 2nd edn. 2010-08-01. ISO International Standard, Geneva

Jalayer F, Cornell CA (2009) Alternative non-linear demand estimation methods for probabilitybased seismic assessments. Earthq Eng Struct Dyn 38:951-972

Karhunen K (1946) Zur spektraltheorie stochastischer prozess. Ann Acad Sci Fenn Math 1:34

Lagomarsino S (2012) Damage assessment of churches after L'Aquila earthquake (2009). Bull Earthq Eng 10(1):73-92

Lagomarsino S (2015) Seismic assessment of rocking masonry structures. Bull Earthq Eng 13:97-128. doi:10.1007/s10518-014-9609-x

Lagomarsino S, Cattari S (2015) guidelines for seismic performance-based assessment of cultural heritage masonry structures. Bull Earthq Eng 13:13-47. doi:10.1007/s10518-014-9674-1 
Lagomarsino S, Modaressi H, Pitilakis K, Bosjlikov V, Calderini C, D'Ayala D, Benouar D, Cattari S (2010) PERPETUATE Project: the proposal of a performance-based approach to earthquake protection of cultural heritage. Adv Mater Res 133-134:1119-1124

Lagomarsino S, Penna A, Galasco A, Cattari S (2013) TREMURI program: an equivalent frame model for the nonlinear seismic analysis of masonry buildings. Eng Struct 56:1787-1799. doi: http://dx.doi.org/10.1016/j.engstruct.2013.08.002

Loeve M (1945) Fonctions aléatoire de second ordre. Comptes Rendus de l'Acadèmie des sciences, Paris, p 220

Lumley JL (1970) Stochastic tools in turbulence. Academic, New York

Marrè Brunenghi M (2014) Probabilistic tools for the qualitative analysis of wind actions on structures, $\mathrm{PhD}$ Thesis, University of Genoa

Mouyiannou A, Rota M, Penna A, Magenes G (2014) Identification of suitable limit states from nonlinear dynamic analyses of masonry structures. J Earthq Eng 18(2):231-267. doi:10.1080/ 13632469.2013 .842190

Oliveira CS (2003) Seismic vulnerability of historical monuments: a contribution. Bull Earthq Eng $1: 37-82$

Petry S, Beyer K (2014) Influence of boundary conditions and size effect on the drift capacity of URM walls. Eng Struct 65:76-88

Priestley MJN, Calvi GM, Kowalsky MJ (2007) Displacement-based seismic design of structures. IUSS Press, Pavia, 721 pp. ISBN:978-88-6198-000-6

Recommendations P.C.M. (2011) Assessment and mitigation of seismic risk of cultural heritage with reference to the Technical Code for the design of constructions, issued by D.M. 14/1/ 2008. Directive of the Prime Minister, 9/02/2011. G.U. no. 47, 26/02/2011 (suppl. ord. no. 54) (in Italian)

Reyes J, Chopra A (2011) Three dimensional modal pushover analysis of buildings subjected to two components of ground motion, including its evaluation for tall buildings. Earthq Eng Struct Dyn 40:789-806

SIA 269/8 (2013) Existing structures - earthquakes, draft. Swiss Society of Engineers and Architects, Zürich

Solari G, Carassale L, Tubino F (2007) Proper orthogonal decomposition in wind engineering: Part 1: A state-of-the-art and some prospects. Wind Struct 10(2):153-176

Sorrentino L, Liberatore L, Decanini LD, Liberatore D (2013) The performance of churches in the 2012 Emilia earthquakes. Bull Earthq Eng 12. doi:10.1007/s10518-013-9519-3

Sullivan T, Calvi GM (2013) Development in the field of displacement based seismic assessment, Ed. IUSS Press (PAVIA) and EUCENTRE, pp 524. ISBN:978-88-6198-090-7

Tomazevic M (1999) Earthquake-resistant design of masonry buildings. Imperial College Press, ISBN 9781860940668

Vamvatsikos D, Cornell CA (2002) Incremental dynamic analysis. Earthq Eng Struct Dyn 31 (3):491-514

Williams M, Sexsmith RG (1995) Seismic damage indices for concrete structures: a state-of-theart review. Earthq Spectra 11(2):319-349 